\title{
Advanced Course in Medical Education and Research: a Leadership Program for Outstanding Graduates
}

\author{
Burgess, $A .{ }^{1}$, Oates, $K^{2}{ }^{2}$, Goulston, $K^{2}{ }^{2}$, Ha Phan Hai $A n^{3}$
}

\begin{abstract}
Introduction: In 2009, the Hoc Mai Advanced Course in Medical Education and Research was established. The Advanced Course is designed to provide a select group of outstanding recent Hanoi Medial University (HMU) graduates with tools to introduce and lead change in medical education and research, contributing to the development of future Vietnamese health care. The aims of the program are to develop participants' knowledge and skills in teaching, competence in spoken and written medical English, skills in research; and provide ongoing support. The purpose of this study was to explore previous participants' (2009-2013) perceptions of the course, and impact on professional development.
\end{abstract}

Methods: In 2015, an anonymous online questionnaire was distributed to 106 Course participants who had participated in both Hanoi and Sydney (2009-2013). Participants were asked to respond to closed and open ended questions. Descriptive statistics were used to analyse data.

Results: Fifty six of the 106 participants (53\%) responded. The Course was overwhelmingly perceived to be beneficial in helping participants with their English speaking skills. Almost half $(45 \%)$ of respondents felt the course helped with their career, teaching of students $(43 \%)$ and junior doctors $(43 \%)$. Regarding research skills, $31 \%$ felt that participation in the course helped in completing a research project, $32 \%$ in presenting at conferences, and $22 \%$ in publishing a paper. Although participants indicated that a helpful aspect of the Course was the opportunity to network with Australian colleagues, they would like more opportunities for future collaboration, and a longer immersion program.

Conclusion: Taking part in the Advanced Course has helped participants' professional development by improving English skills, teaching skills, research skills and career progression. However, improvements are needed in terms of further ongoing assistance with research and continued contact with Australian experts.

\section{Introduction}

The Hoc Mai (forever learning) Foundation based at The University of Sydney was established in 2001 to improve health outcomes in Vietnam through education and research and to foster relationships between Vietamese and Australian healthcare providers.

\footnotetext{
${ }^{1}$ Education Office, Sydney Medical School, The University of Sydney, New South Wales, Australia.

${ }^{2}$ Sydney Medical School, The University of Sydney, New South Wales, Australia.

${ }^{3}$ Hanoi Medical University, Hanoi, Vietnam.

Corresponding Author:

Annette Burgess, Associate Professor, The Education Office, Sydney Medical School, Room 205, Edward Ford Building A27, The University of Sydney,

Sydney NSW 20006, Australia

Email: annette.burgess@sydney.edu.au
}

DOI: http://doi.org/10.4038/seajme.v12i1.36
The Foundation brings together collective health care knowledge, skills and expertise to form an Australian and Vietnamese educational collaboration. A priority of the Hoc Mai Foundation is to identify and provide training for potential Vietnamese healthcare leaders. Since its inception, various activities and projects have taken place, resulting in growing relationships and strong ties. For example, the Foundation supports educational programs in Vietnamese hospitals and universities, and student and health professional exchange between Australia and Vietnam.

In 2009 a workshop at Hanoi Medical University was held to determine educational priorities to which Hoc Mai could contribute. The workshop was attended by the Rector of 
the University, senior academic staff, clinicians and educators as well as three of the authors of this paper ( $\mathrm{KG}, \mathrm{KO}$ and $\mathrm{HPHA}$ ) with the aim of determining educational priorities to which Hoc Mai could contribute. Four areas were identified: (a) teaching medicine and medical skills in English (b) defining learning objectives (c) introducing new teaching methods (d) introducing new methods of assessment. Research methods and publication of research were subsequently added. The Advanced Course was developed as a response to the needs identified in this workshop (Dent et al., 2013).

The Hoc Mai Advanced Course in Medical Education and Research (Advanced Course) is designed to provide a select group of outstanding recent Hanoi Medical University (HMU) graduates with the tools to introduce and lead change in medical education and research, thereby contributing to the development of Vietnamese health care for the future. It emphasises skills not widely taught to Vietnamese medical students and graduates, but which are essential for future leadership and career development. These include: change management, modern assessment methods of medical skills, clinical skills, teaching skills, using a simulation centre to enhance teaching, statistics, evidence based medicine, research methods, leading and sustaining change, ethics and professionalism, preparing projects for publication, communication skills and patient safety. Teaching throughout the course is studentcentred and interactive, using small group discussions and one-on-one interactions. All teaching and student-teacher interactions are in English.

In Vietnam, doctors usually go into training in their chosen specialty soon after graduation so that those selected for the course come from a wide range of specialities. For this reason the topics taught in the course are generic topics, useful for any speciality.

The program aims to:

1. Develop knowledge and skills in teaching by providing an advanced educational experience that equips participants for leadership, management and innovative change in medical education and research.

2. Develop competence in spoken and written medical English, enabling participants to teach in English, publish in
English language journals and communicate in English with international colleagues as teachers and researchers.

3. Develop skills in evaluating research, and developing and publishing local research projects.

4. Provide ongoing support for participants once they return to their usual professional responsibilities so that they can apply what they have learned and lead change in medical education, research and health care.

5. Link Vietnamese doctors participating in the Advanced Course with Australian Clinical Academics in the same specialty so that ongoing contact can occur after the conclusion of the course.

The purpose of this study was to explore previous participants' (2009-2013) perceptions of the course, and the impact the course has had on their professional development.

\section{Course participants}

The course is run on an annually across one year. Each year, 50 potential participants are invited to apply by the President of the HMU on the basis of their academic record at HMU and the Residency examination. Applicants are interviewed by two Clinical Academics from Sydney Medical School (SMS) who have access to the applicants' curricula vitae. The interview uses a structured format to assess their comprehension of spoken English, ability to speak English and commitment to lead change in medical education and research. The 25 to be included in the course are selected on this basis.

The Advanced Course has three components, where the aforementioned future leadership and career development skills are taught throughout (including change management, modern assessment methods of medical skills, clinical skills, teaching skills, using a simulation centre to enhance teaching, statistics, evidence based medicine, research methods, leading and sustaining change, ethics and professionalism, preparing projects for publication, communication skills and patient safety):

1) Teaching in Hanoi, Vietnam

Five times each year, a team of two or more clinical academics from SMS travels to Hanoi 
to teach the local component of the course. Teaching is done in the evenings after the HMU doctors finish work.

During the day the SMS academics have the opportunity to visit HMU hospitals for ward rounds or to teach in their area of expertise.

\section{2) An Immersion in Sydney, Australia}

A key component of the program is the immersion course held between July and August in Sydney. This is a five week intensive course held at the Royal North Shore Hospital for 15-25 of the course participants who have shown commitment and leadership during the Hanoi teaching. The format of the intensive course comprises two weeks of interactive, generic teaching, including presentations by course participants. This is followed by clinical placements in each Vietnamese doctor's areas of expertise. In these placements they spend up to two weeks attending ward rounds and clinics with a Sydney University clinical academic from their own specialty. As well as gaining clinical insights, they help their Australian colleagues to learn about health care in Vietnam. They are encouraged to discuss developing joint Australia-Vietnam research projects and to keep in touch after the attachment.

3) A virtual classroom to provide monthly teaching

To complement the face to face teaching, an online component was added to the course in 2013. Using Citrix software that creates a virtual classroom over the internet that links Australia and Vietnam together, an hour long lecture (during the doctors' lunchbreak) was scheduled once a month between March and July. Each lecture was unique, covering a specific topic from guest lecturers focusing on topics such as 'Recognising depression', 'Prevention of hospital infection', 'Managing the patient with cancer', 'Safety behaviours in the clinical setting', and 'Radiology in 2030'.

Each phase of the course is formally evaluated by participants using structured questionnaires. Modifications to the next course are influenced by the feedback the evaluation provides (Dent et al., 2013). The total cost of the course was initially funded by Australian donors. In recent years funding for the Immersion component of the course has been awarded through the competitive grant program of the Australian Department of Foreign Affairs and Trade.

\section{Methods \\ Data collection and analysis}

In 2015, an anonymous online questionnaire was distributed using Lime Survey to the 106 who had participated in both the Hanoi and Sydney components of the Advanced Course between 2009 and 2013.

To reach those who had not responded, reminders were sent over the next six weeks. Participants were asked to respond to 10 closed questions, using a five-point Likert scale ranging from 'strongly disagree' (1) to 'strongly agree' (5). Data were analysed using descriptive statistics (Creswell, 2002). Open ended questions were included in the questionnaire to identify participants' perceptions of the program. Thematic analysis was used to code, categorise and identify themes in the qualitative data (Braun \& Clarke, 2006). Data within themes were then counted to determine prevalence.

\section{Ethics approval}

Ethics approval was granted by the University of Sydney Human Research Ethics Committee.

\section{Results}

Fifty six of the 106 participants $(53 \%)$ of participants who had undertaken the course between 2009 and 2013 responded to the questionnaire. Of the respondents, $52 \%$ were female. The age range of respondents at the time of completing the survey was $26-55$. Of the respondents, $12 \%$ had undertaken the Course in 2009; $15 \%$ in $2010 ; 17 \%$ in 2011 ; 25\% in 2012; and 31\% in 2013.

Participant responses regarding the impact of the course on professional life are illustrated in Figure 1 andTable 1.

The Advanced Course was overwhelmingly perceived to be beneficial in helping participants with their English speaking skills, with $98 \%$ either Strongly Agreeing or Agreeing with this statement.

Almost half $(45 \%)$ of all respondents felt the course helped with their career overall $(25 \%$ agreeing that the course helped them to gain a promotion, and $24 \%$ that the course had helped to gain an overseas scholarship). Forty six percent Strongly Agreed or Agreed that the course had helped in teaching medical 
students, and $43 \%$ that it helped in their teaching of junior doctors. Regarding research skills, 31\% Strongly Agreed or Agreed that participation in the course had helped in completing a research project, $32 \%$ in presenting at conferences, and $22 \%$ in publishing a paper.

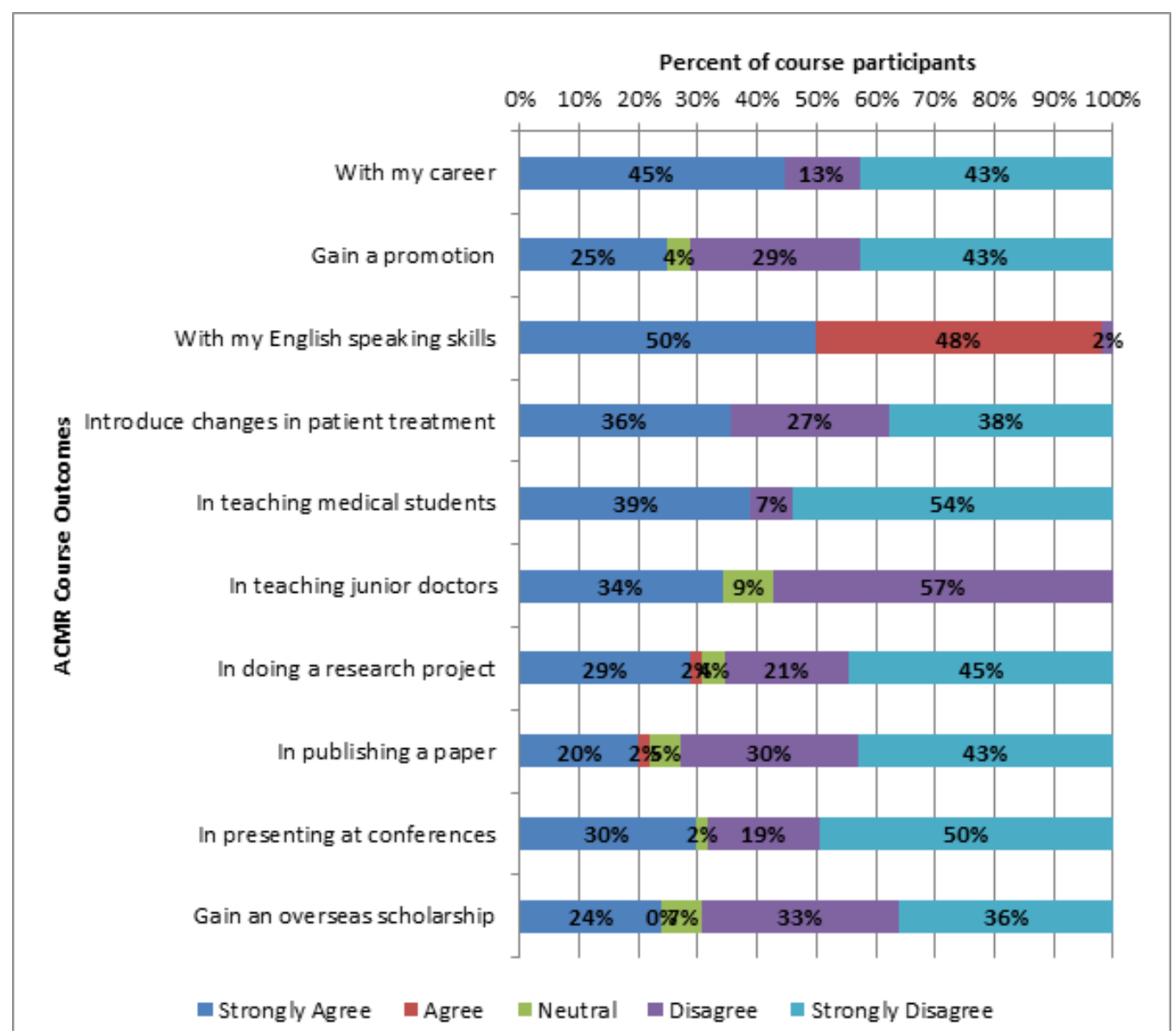

Figure 1: Participants' perception of ACMR course outcomes, displayed as percentages (N=56)

Table 1: Participants' perceptions of ACMR course outcomes ( $N=56)$

\begin{tabular}{lccccc}
\hline & $\begin{array}{c}\text { Strongly } \\
\text { Agree }\end{array}$ & Agree & Neutral & Disagree & $\begin{array}{c}\text { Strongly } \\
\text { Disagree }\end{array}$ \\
\hline With my career & 44.643 & & & 12.500 & 42.857 \\
Gain a promotion & 25.000 & & 3.571 & 28.571 & 42.857 \\
With my English speaking skills & 50.000 & 48.214 & & 1.786 & \\
Introduce changes in patient treatment & 35.714 & & & 26.786 & 37.500 \\
In teaching medical students & 39.286 & & & 7.143 & 53.571 \\
In teaching junior doctors & 33.929 & & 8.929 & 57.143 & \\
In doing a research project & 28.571 & 1.786 & 3.571 & 21.429 & 44.643 \\
In publishing a paper & 19.643 & 1.786 & 5.357 & 30.357 & 42.857 \\
In presenting at conferences & 29.630 & & 1.852 & 18.519 & 50.000 \\
Gain an overseas scholarship & 23.636 & 0.000 & 7.273 & 32.727 & 36.364 \\
\hline
\end{tabular}

Note, due to the relatively low sample size and to facilitate clarity, percentages were provided in whole numbers. When rounded, the sum of some of these numbers equal 101. Responses to qualitative questions indicated that the majority of participants (98\%) found one of the most helpful aspects of the program to be development of English and Communication skills. Participants also noted that the course had benefited them in development of four key areas 1) Research skills (61\%), 2) Clinical knowledge and patient treatment $(47 \%), 3)$ 
Teaching skills (34\%), and 4) Presentation skills $(21 \%)$. Although $21 \%$ of participants indicated that a helpful aspect of the Course was the opportunity to network with Australian colleagues, the same number $(21 \%)$ indicated that they would like greater opportunities for future collaboration. Additionally, $21 \%$ of participants indicated that they would prefer a longer Immersion program, with additional time for observation in the clinical setting.

\section{Discussion}

The purpose of this study was to explore participants' perceptions of the Hoc Mai Advanced Course in Medical Education and Research, and impact on their professional development, two to five years after completion. Participants identified benefits to the program, made suggestions for improvement, and mentioned challenges encountered since completion of the program. Participants generally perceived the greatest benefits of the program to be an improvement in English, assisting with their careers, and with their teaching skills. While a large number of candidates felt the course had helped to develop their research skills, there was a perceived need for increased ongoing assistance. The findings from our study are discussed based on the program outcomes.

\section{Influence on English skills}

With regard to career development, the Advanced Course was perceived to be most beneficial in helping participants with their English speaking skills. Analysis of qualitative data is supportive of this, with candidates commenting that English skills developed through the course had helped, particularly with communication in healthcare and teaching. This is important for Vietnamese doctors wishing to advance their careers as English is recognized as the international language of medicine (Maher, 1986). The engagement of the clinicians in an innovative setting to develop skills in English and communication is essential, as they will utilise these skills in their professional lives. With our increasingly complex healthcare systems (Frenk et al., 2010), it is important to emphasise the teaching of communication skills (Platt, 2010). Early training and experience has many potential benefits, including improvements in leadership and collaboration between healthcare teams, ultimately improving patient safety (Brock et al., 2013; Reeves et al., 2013).

\section{Influence on teaching skills}

The course increased participants' perceived ability and confidence to teach. A significant proportion of participants felt the Advanced Course assisted in their teaching skills for either medical students (43\%) or junior doctors $(36 \%)$ (Figure 1). This quantitative data is reinforced by qualitative responses, with $34 \%$ of participants referencing teaching skills as being one of the primary benefits of completing the course. While medical practitioners are expected to supervise, teach, assess and provide feedback to colleagues and contribute to the teaching of future generations of medical students, these skills are rarely taught in medical schools (Gibson \& Campbell, 2000). The shift from teacher centred to student centred approaches to education is recognised as key to successful teaching. By reflection and development of teaching skills, clinicians can improve their impact on future students and peers, highlighting the importance of skills development in this area (Burgess et al., 2014). Additionally, by placing an emphasis on teaching skills throughout the course, the importance of the clinicians' own role as educators in their future health care careers is emphasized (Burgess et al., 2014).

\section{Influence on research and publications}

Approximately one third (35\%) of participants found the Advanced Course to be helpful with their research and publication skills (Figure 1). This is reinforced by the qualitative comments, with respondents commenting that research skills were one of the most helpful aspects of the course. Medical practitioners are expected to be life long learners, as they engage in meeting the healthcare needs of patients in an environment where knowledge and technological advances rapidly change (Hojat et al., 2003). Whether applied to decisions regarding clinical practice, in carrying out scientific studies, or in making decisions around health care policies, research skills, and critical appraisal skills are essential to best practice in patient care. Critical appraisal skills are those taught to allow healthcare professionals to evaluate research and the published literature. These skills are crucial in ensuring evidence based practice (CEBM, 2017). Critical appraisal is the careful and systematic evaluation of literature which aims to identify flaws allowing readers to judge and make an informed decision about the quality of research presented. It involves assessing the validity, strengths/weaknesses, and clinical 
importance or usefulness of research finding (CEBM, 2017s. Promotion of extended collaboration and networking in research between Australian and Vietnamese health professionals may further improve research output, and use of best evidence in decision making, ultimately benefiting patient care.

\section{Overall influence on career}

It is expected that development of skills in English, teaching and research contribute to the advancement of career opportunities. Half $(51 \%)$ of participants felt the course helped with their career generally, and a quarter $(25 \%)$ reported that the course helped them to gain a promotion. It is important to note that within qualitative responses, a large proportion $(21 \%)$ of respondents indicated that they would like greater opportunity for further collaboration with Australian health professionals. Although provision of training is important, effective clinical leaders and managers, need to be nurtured and supported by the organisations in which they train and work (McKimm \& Swanwick). Establishing pathways to increase ongoing support for participants may help to improve their career outcomes.

\section{Limitations}

A limitation of the study is the response rate of $56 / 106(53 \%)$. This may have been due to the mobility and frequent changes of email addresses of Vietnam doctors in the early years after graduation.

One area where there could be more emphasis is fostering relationships between the Vietnamese doctors who do a clinical attachment in Sydney as part of the Immersion component and their Australian colleagues in the same specialty. There could be more emphasis on supporting joint research projects and follow-up visits, from Australia to Vietnam as well as from Vietnam to Australia.

\section{Conclusion}

Attendance at the Advanced Course has helped participants' professional development by improving English skills, communication skills, teaching skills, research skills and career progression. However, improvements are needed in terms of further ongoing assistance with research and continued contact with Australian experts.

\section{Acknowledgement}

The authors thank Professor Nguyen Duc Hinh and Professor Dang Van Duong from Hanoi Medical University, for their ongoing support, Tyler Clark from Sydney University for expert assistance with the survey instrument and statistical analysis and the generous donors who support the Vietnam component of the program.

\section{References}

Braun, V.\& Clarke, V. (2006). Using thematic analysis in psychology, Quality Research in Psychology, 3, 2, pp. 77-101.

Brock, D., Abu-Rish, E., Chiu, C.R., Hammer, D., Wilson, S., Vorvick, L., Blondon, K., Schaad, D., Liner, D. \& Zierler, B. (2013) Interprofessional education in team communication: working together to improve patient safety, Postgraduate Medical Journal, 89, 1057, pp. 642-651.

Burgess, A., Oates, K.\& Goulston, K. (2016) Role modelling in medical education: the importance of teaching skills, The Clinical Teacher, 13, 2, pp. 134-137.

Centre for Evidence Based Medicine (2017) University of Oxford, Available at: http://www.cebm.net/critical-appraisal/

[Accessed 24 April, 2017].

Creswell, J.W. (2002) Educational Research: Planning, conducting and Evaluating Quantitativeand qualitative Research, pp. 146166, Upper Saddle River, NJ, USA: Merrill.

Dent, O.F., Goulston, K., Oates, R.K., Dang, V.D. \& Nguyen, D.H. (2013) A short course in advanced medical teaching for talented Hanoi Medical University Graduates, Journal of South East Asian Journal of Medical Education, 7, 2, pp. 2-5.

Frenk, J., Chen, L., Bhutta, Z.A., Cohen, J., Crisp, N., Evans, T., Fineberg, H., Garcia, P., Ke, Y., Kelly, P. \& Kistnasamy, B. (2010) Health professional for a new century: transforming education to strengthen health systems in an indepedent world, The Lancet, 376, 9756, pp. 1923-1958.

Gibson, D.R. \& Campbell, R.M. (2000) Promoting effective teaching and learning: hospital consultants identify their needs, Medical Education, 34, 2, pp. 126-130.

Hojat, M., Nasca, T.J., Erdmann, J.B., Frisby, A.J., Veloski, J.J. \& Gonnella, J.S. (2003) An operational measure of physician lifelong learning: its development, components and preliminary psychometric data, Medical Teacher, 25, 4, pp. 433-437. 
Maher, J. (1986) The Development of English as an International Language of Medicine, Applied Linguistics, 7, 2, pp. 206-218.

McKimm, J., \& Swanwick, T. (2011) Leadership development for clinicians: what are we trying to achieve? The Clinical Teacher, 8, 3, pp. 181185.
Platt, A. (2010) Teaching medicine to millennials, The Journal of Physician Assistant Education, 21, 2, pp. 42-44.

Reeves, S., Perrier, L., Goldman, J., Freeth, D. \& Zwarenstein, M. (2013) Interprofessional education: effects on professional practice and health care outcomes (update), The Cochrane Library. 